\section{(2) OPEN ACCESS}

\title{
Associations between tobacco control mass media campaign expenditure and smoking prevalence and quitting in England: a time series analysis
}

\author{
Mirte A G Kuipers, ${ }^{1,2}$ Emma Beard, ${ }^{1,3}$ Robert West, ${ }^{1}$ Jamie Brown ${ }^{1,3}$
}

\begin{abstract}
- Additional material is published online only. To view, please visit the journal online (http://dx.doi.org/10.1136/
\end{abstract} tobaccocontrol-2017-053662).

${ }^{1}$ Department of Epidemiology and Public Health, University College London, London, UK ${ }^{2}$ Department of Public Health, Amsterdam Public Health

Research Institute, Academic Medical Center, University of Amsterdam, Amsterdam, The Netherlands

${ }^{3}$ Research Department of Clinical, Educational and Health Psychology, University College London, London, UK

\section{Correspondence to}

Mirte A G Kuipers, Department of Public Health, Academic Medical Center - University of Amsterdam, P.O. Box 22660,

1100 DD, Amsterdam, The Netherlands;

m.a.kuipers@amc.uva.nl

Received 24 January 2017

Revised 6 May 2017

Accepted 30 May 2017

Published Online First

30 June 2017

\begin{abstract}
Background It has been established that mass media campaigns can increase smoking cessation rates, but there is little direct evidence estimating associations between government expenditure on tobacco control mass media campaigns and smoking cessation. This study assessed the association over 8 years between mass media expenditure in England and quit attempts, smoking cessation and smoking prevalence.

Methods Autoregressive integrated moving average modelling with exogenous variables (ARIMAX) was applied to monthly estimates from the Smoking Toolkit Study between June 2008 and February 2016. We assessed the association between the trends in mass media expenditure and (1) quit attempts in the last two months, (2) quit success among those who attempted to quit and (3) smoking prevalence. Analyses were adjusted for trends in weekly spending on tobacco by smokers, tobacco control policies and the use of established aids to cessation.

Results Monthly spending on mass media campaigns ranged from nothing to $\mathrm{f} 2.4$ million, with a mean of $£ 465$ 054. An increase in mass media expenditure of $10 \%$ of the monthly average was associated with a $0.51 \%$ increase (of the average) in success rates of quit attempts ( $95 \% \mathrm{Cl} 0.10 \%$ to $0.91 \%, \mathrm{p}=0.014$ ). No clear association was detected between changes in mass media expenditure and changes in quit attempt prevalence $(\beta=-0.03,95 \% \mathrm{Cl}-2.05 \%$ to $2.00 \%$, $p=0.979)$ or smoking prevalence $(\beta=-0.03,95 \% \mathrm{Cl}$ $-0.09 \%$ to $0.03 \%, p=0.299$ ).
\end{abstract}

Conclusion Between 2008 and 2016, higher monthly expenditure on tobacco control mass media campaigns in England was associated with higher quit success rates.

\section{INTRODUCTION}

The WHO's Framework Convention on Tobacco Control mandates countries to promote 'public awareness about the health risks of tobacco consumption and exposure to tobacco smoke, and about the benefits of the cessation of tobacco use and tobacco-free lifestyles'. ${ }^{1}$ Tobacco control mass media campaigns aim to raise the salience of the harmful effects of smoking, promote quitting, and often provide information on how to obtain help to quit. ${ }^{2}$ Tobacco control mass media campaigns are considered to be an important part of a comprehensive tobacco control strategy ${ }^{3}$ due to their potential impact ${ }^{4-6}$ by decreasing cigarette consumption $^{78}$ and smoking prevalence ${ }^{7-9}$ and increasing quitting-related behaviours. ${ }^{10-13}$
In spite of the available evidence, there remains the crucial question as to what effect can be achieved for a given level of expenditure on tobacco control mass media campaigns by national governments. ${ }^{14}$ A review of 10 studies reported that mass media campaigns are cost-effective in terms of life years or quality-adjusted life-years gained. ${ }^{15}$ However, evidence is largely limited to studies of specific campaigns and expenditure over a relatively short period of time. ${ }^{16-19}$ Evaluations of expenditure over a more extended period have been conducted in the USA, where they found a positive association with calls to quitlines ${ }^{20}$ and a negative association with cigarette sales. ${ }^{21}$ Moreover, a freeze on mass media expenditure in the UK was associated with a decrease in the use of smoking cessation literature, quitline calls and hits on the national smoking cessation website. ${ }^{10}$ However, there is little evidence linking expenditure and actual quitting. Evaluations of specific campaigns such as No Smoking Day ${ }^{22}$ or Stoptober ${ }^{17}$ may provide different results from an analysis of mass media spending extending over a period of a year or more.

The US Centers for Disease Control (CDC) Best Practices for Comprehensive Tobacco Control Programs recommend an investment in tobacco control mass media campaigns of $\$ 0.65$ to $\$ 1.95$ per person per year. ${ }^{23}$ England has for the past 15 years had a strong tobacco control climate ${ }^{24}$ and has run mass media campaigns for most of that time, although not at the level recommended by the CDC. In recent years, spending on campaigns in England has varied markedly, including a moratorium on spending on major 'above the line' campaigns (that is, campaigns using traditional forms of media) when the Conservative-Liberal Democrat coalition came to power in 2010-2011. ${ }^{10}$ This 'natural experiment' provides a unique opportunity to study the impact of mass media spending across a wide range of values over a period of years.

This study aimed to assess the associations between changes in mass media tobacco control expenditure in England and changes in population-level quit attempt rates, smoking cessation rates and smoking prevalence. These outcome measures address the hypotheses that mass media campaigns may encourage smokers to attempt quitting, could lead to more successful smoking cessation and lower smoking prevalence. We included data on mass media expenditure before and after the 2010-2011 moratorium, which provided us with a large variation in expenditure data. With the use of the Smoking Toolkit Study, involving monthly cross sectional surveys of representative samples of the 
adult population of England, we were able to compare expenditure trends with trends in smoking behaviour while adjusting for important developments in tobacco spending, use of cessation aids and tobacco control over time. This provides information that complements previous evaluations of tobacco control mass media campaigns. ${ }^{15}$

\section{METHODS}

\section{Data and study population}

Data were obtained from 165420 individuals between June 2008 and February 2016 taking part in Smoking Toolkit Study (STS), a population survey of adults aged $16+$ (www.smokinginengland.info). In the STS, each month a new sample of approximately 1800 adults aged $\geq 16$ years is selected using a form of random location sampling. Individuals complete a face-to-face computer-assisted household interview survey with a trained interviewer. The STS samples have been shown to be nationally representative in their sociodemographic composition and proportion of smokers in the population 16+. Ethical approval was granted by the University College London ethics committee. Full details of the STS methods have been described elsewhere. ${ }^{25}$

\section{Measures}

\section{Smoking behaviour}

Smoking was measured with the question: "Which of the following best applies to you?', with response options: (1) 'I smoke cigarettes (including hand-rolled) every day', (2) 'I smoke cigarettes (including hand rolled), but not every day', (3) 'I do not smoke cigarettes at all, but I do smoke tobacco of some other kind', (4) 'I have stopped smoking completely in the last year', (5) 'I have stopped smoking completely more than a year ago', (6) 'I have never been a smoker (ie, I have never smoked for a year or more)'. Last-year smokers were defined as individuals selecting answers 1 through 4 . Individuals selecting options 1 through 3 were considered to be current smokers. Smoking prevalence was measured as the proportion of current smokers in the total population.

Quit attempts in the last 2 months were measured among lastyear smokers who answered: 'How many serious attempts to stop smoking have you made in the last 12 months?', and if one or more attempts were reported: 'How long ago did your most recent serious quit attempt start?'. We distinguished those who attempted to quit up to 2 months ago versus those who made no quit attempt or attempted to quit more than 2 months before the interview but were not successful. Last-year smokers who had successfully quit smoking more than 2 months before the interview were excluded for the analysis on quit success.

Successful quit attempts in last 2 months were defined as last-year smokers who attempted to quit in the last 2 months (defined as described above) who were still not smoking at the time of the interview. This only represents short-term success, but to go back further would have increased the risk of bias from forgotten quit attempts, ${ }^{26}$ and long-term quit success in large samples can be reliably estimated from short-term success. The relapse rate between 1 month and 1 year is approximately $70 \%$, and between 1 year and 10 years is approximately $30 \% .{ }^{27}$

\section{Mass media expenditure}

Data on tobacco control campaign expenditure in England were provided by Public Health England. Total spending on campaigns was provided for each period in which the campaign ran, which in many cases included multiple months. Spending (in million $£$ ) on 'Smokefree' campaigns, Stoptober campaigns and
Health Harms campaigns were summed and monthly expenditure was extracted. Monthly totals included expenditure on TV, radio, print, cinema and online advertisements. In the months in which there was no campaign running and thus no campaign expenditure reported, Public Health England (PHE) confirmed that campaign expenditure could be regarded as effectively zero, and thus expenditure values were set to a nominal value of 0.01 ( $£ 10000$; zero values cannot be modelled). Expenditure figures diverge from those reported earlier (eg, in Action on Smoking and Health (ASH) publications ${ }^{28}$ ), as 'lead generation' expenditure was included in the ASH figures but not in the present study. Lead generation involved using databases to attempt to route individual smokers to stop smoking services.

\section{Potential confounding variables}

We included a variable reflecting the course of tobacco control policies in England. The value of the tobacco control variable increased by one unit with the introduction of each new policy in the study period (June 2008-February 2016) and was assigned to the month of when the policy was implemented. Over time, the variable values ranged from 1 to 7 , with one point added when each of the following six tobacco control policies were implemented: (1) October 2009: pictorial warnings on cigarette packs, (2) October 2010: pictorial warnings on all tobacco products, (3) October 2011: ban on sale of tobacco from vending machines, (4) October 2013: ban advertising at the point of sale, (5) April 2013: ban on displaying cigarette packs in large shops, (6) April 2015: ban on displaying cigarette packs in small shops. As this variable was 'differenced' in the analysis (see Statistical Analysis), it amounted to an impulse of 1 in a month in which a new policy was introduced versus 0 in all other months.

Current smokers estimated their weekly spending on tobacco (in $£$ ). Weekly spending was adjusted for inflation using UK Consumer Price Index (CPI) information from the Office of National Statistics: adjusted spending $=($ spending $/ \mathrm{CPI}) \times 100$. Weekly spending was missing for survey waves between July 2009 and July 2010, for which a linear trend in mean spending is imputed.

The use of any cessation aids in a quit attempt including prescription medication (varenicline or bupropion), prescription nicotine replacement therapy (NRT) or electronic cigarettes (e-cigarettes) were measured among last-year smokers attempting to quit. The use of e-cigarettes, prescribed NRT, varenicline and bupropion have previously been shown to support successful quitting in this population. ${ }^{29}{ }^{30}$ Use of NRT bought over the counter in quit attempts has not been found to increase quit rates in this population ${ }^{29}$ and was therefore not included.

\section{Statistical analysis}

The analysis plan was registered on the Open Science Framework prior to data analysis (https://osf.io/gudrv/). An amendment was made to the analysis plan subsequently. The decision was made not to conduct the subgroup analyses due to the complexity of the overall results in terms of the number of lags and presence of autocorrelation.

Data were aggregated monthly as weighted means or proportions and analysed between April and July 2016 in R V.3.3.2. Means and proportions were weighted for gender, working status, prevalence of children in the household, age, social grade and region, as described in Fidler et al. ${ }^{25}$

We applied Autoregressive Integrated Moving Average (ARIMA) with Exogenous Input (ARIMAX) modelling, which is comparable to methods used in other tobacco control 
evaluation studies. ${ }^{9}{ }^{12}$ ARIMAX is similar to ARIMA analysis, in that it uses forecasts based on prior values in the time series (autoregressive terms (AR)) and errors made by previous predictions (moving average terms (MA)). Additionally, ARIMAX can assess associations between multiple time series, allowing control for other processes taking place over time. We followed a standard ARIMAX modelling approach which is given in more detail in the preregistered analysis plan. ${ }^{31}$

Time series analysis requires stationary data. To achieve this, the series are first log transformed to stabilise the variance and, if required, are differenced and seasonally differenced. The differenced value of $\mathrm{Y}$ at month $\mathrm{t}$ would be $\mathrm{Y}_{\mathrm{t}-\mathrm{Y}-1}$ and the seasonally differenced value would be $\mathrm{Y}_{\mathrm{t}-\mathrm{Y}} \mathrm{t}_{-12}$. Differencing attempts to remove underlying linear and cyclical trends. The autocorrelation and partial autocorrelation functions were examined to determine the seasonal and non-seasonal MA and AR. To identify the most appropriate transfer function for the continuous explanatory variables, the sample cross-correlation function was checked for each ARIMAX model. ARIMAX models with several combinations of values for $p$ (the number of autoregressive terms) and q (the number of lagged forecast errors), and several lags were run, and the models with the best fit were presented. Additionally, a model without lag for mass media expenditure was estimated. A detailed explanation of the model selection is available in the online supplementary material. Coefficients can be interpreted as estimates of the percentage change in the mean outcome of interest across the study period for every percentage increase in mass media expenditure above the monthly mean across the study period. In the tables, the coefficients were multiplied by 10 to represent the change with a $10 \%$ increase in expenditure. STROBE guidelines were followed. ${ }^{32}$

In sensitivity analyses, we tested models without lags for all covariates and models with additional AR and MA terms. In all sensitivity analyses, the results for mass media expenditure were compared with the results of the main analysis.

\section{RESULTS}

Descriptive statistics are presented in table 1 , figure 1 and figure 2. Over the period June 2008 to February 2016, Public Health England spent $£ 43.2$ million on tobacco control mass media campaigns. As depicted in figure 1, expenditure varied over the years, and was generally high in 2008 and 2009, after which it dropped to zero during a moratorium on spending. Expenditure resumed in 2012 to 2015. Table 1 and figure 1 show that the weighted smoking prevalence over the total study period was $20.6 \%$ (95\% CI $20.4 \%$ to $20.8 \%$ ) and that it decreased over time. The 2 -month quit attempt rate (percentage of smokers having made a quit attempts in the past 2 months) over the total period was $10.3 \%$ (95\% CI $9.9 \%$ to $10.6 \%)$ and somewhat increased over time, while quit success among those who attempted to quit did not show a clear linear trend and fluctuated around 20\% (table 1 and figure 1). The use of cessation aids rapidly increased (table 1 and figure 2).

Table 2 shows the percentage change in quit attempts for a $10 \%$ increase in mass media expenditure above the monthly average, as estimated in the ARIMAX models. Mass media expenditure was not significantly associated with concurrent change in quit attempts rates (per cent change $-0.04,95 \%$ CI -0.63 to 0.54 , $\mathrm{p}=0.883$ ), nor was it significantly associated with quit attempts 2 months later (per cent change $-0.05,95 \%$ CI -0.67 to 0.56 , $\mathrm{p}=0.861$ ). Results were similar in the unadjusted and adjusted models. Table 2 also shows that the quit attempt rate was not associated with smokers' weekly spend on tobacco or with tobacco control policies.

Table 3 shows ARIMAX results for quit success. With every $10 \%$ increase in mass media expenditure above the monthly average, successful smoking cessation among quitters immediately increased by $0.55 \%(95 \%$ CI 0.15 to $0.96, p=0.007)$ in the unadjusted model and by $0.51 \%(95 \%$ CI 0.10 to $0.91, \mathrm{p}=0.014)$ in the adjusted model. A lag of 1 month for mass media expenditure, although with a lower model fit, led to a comparable increase in quit success (per cent change 0.49 , 95\% CI 0.10 to $0.87, \mathrm{p}=0.013)$. Covariates did not show significant associations with quit success.

Table 4 shows ARIMAX results for smoking prevalence. A significant decrease in smoking prevalence in response to mass media expenditure was not observed and results were the same for models without a lag and with a lag of 2 months (percent change $-0.03,95 \% \mathrm{CI}-0.09$ to $0.03, \mathrm{p}=0.299$ ). Covariates did not show significant associations with smoking prevalence, although the use of cessation aids tended to be associated with lower smoking rates (percent change $-0.18,95 \% \mathrm{CI}-0.39$ to 0.03, $\mathrm{p}=0.097)$.

\section{DISCUSSION \\ Key findings}

Government spending on mass media campaigns ranged from nothing to $£ 2400000$ per month. No clear association was detected between changes in mass media expenditure and changes in concurrent quit attempts, quit attempts in the following 2 months or smoking prevalence. However, every $10 \%$ increase in mass media expenditure above the monthly average was associated with a $0.51 \%$ increase from the average in short-term success of quit attempts.

Table 1 Description of national tobacco control mass media expenditure and weighted individual level variables by survey period, in \% with $95 \% \mathrm{Cl}$, unless otherwise specified

\begin{tabular}{|c|c|c|c|c|}
\hline & $\begin{array}{l}\text { Total June 2008- } \\
\text { February } 2016\end{array}$ & $\begin{array}{l}\text { June 2008-December } \\
2010\end{array}$ & $\begin{array}{l}\text { January 2011-December } \\
2013\end{array}$ & $\begin{array}{l}\text { January 2014-February } \\
2016\end{array}$ \\
\hline Mass media expenditure (total in million $\mathrm{f}$ ) & 43.2 & 15.2 & 14.0 & 14.1 \\
\hline In the total population, $\mathrm{N}$ & 165420 & 56355 & 65443 & 43622 \\
\hline Current smoking & $20.6(20.4-20.8)$ & $22.1(21.8-22.5)$ & $20.4(20.1-20.7)$ & $19.0(18.6-19.4)$ \\
\hline In smokers, $\mathrm{N}$ & 37013 & 13120 & 14331 & 8487 \\
\hline Quit attempts & $10.3(9.9-10.6)$ & $10.0(9.5-10.6)$ & $10.4(9.9-11.0)$ & $10.4(9.7-11.1)$ \\
\hline 2-month quit success in those who attempted to quit & $19.9(18.5-21.3)$ & $20.2(18.0-22.7)$ & $18.8(16.7-21.1)$ & $21.0(18.2-24.1)$ \\
\hline Cessation aids use & $28.2(27.4-29.1)$ & $18.7(17.6-19.9)$ & $28.8(27.5-30.2)$ & $42.6(40.6-44.5)$ \\
\hline Weekly spend tobacco (mean in $\mathrm{f}, 95 \% \mathrm{Cl}$ ) & 20.9 (20.7 to 21.1$)$ & 19.9 (19.5 to 20.2$)$ & 21.1 (20.8 to 21.4$)$ & $21.6(21.2$ to 22.0$)$ \\
\hline
\end{tabular}




\section{A. Quit attempts}

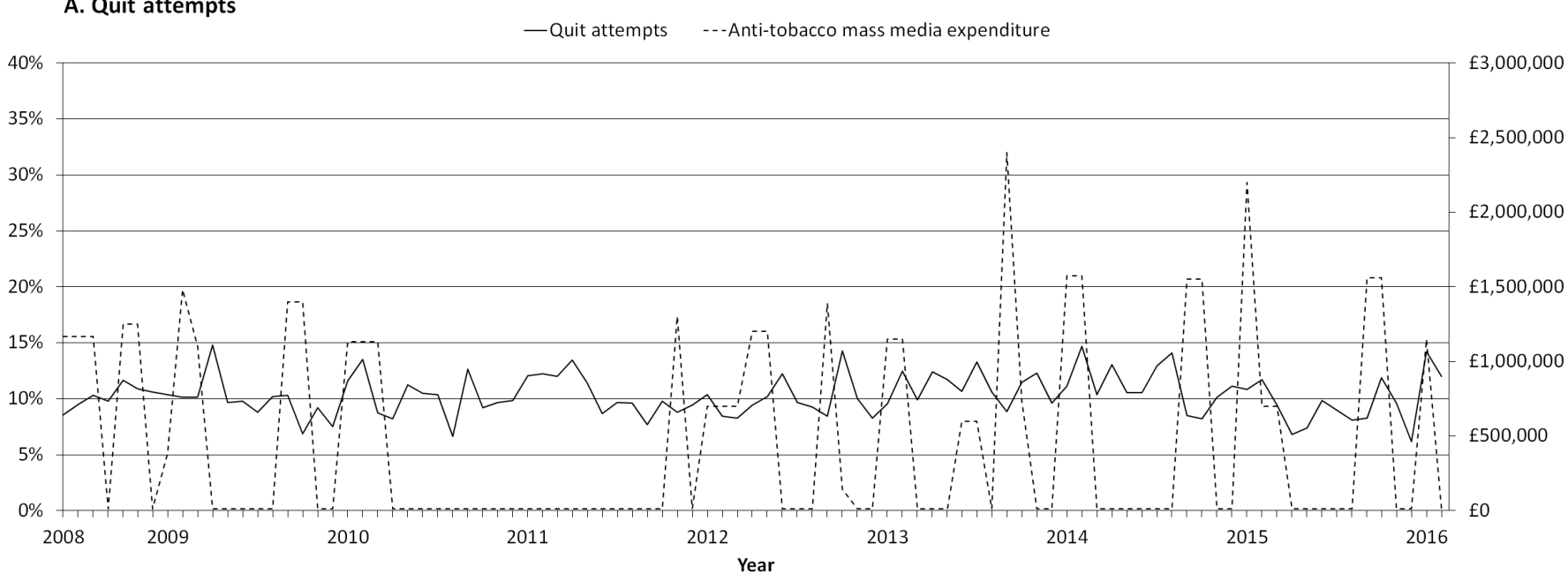

B. Quit success

-Quit success ---Anti-tobacco mass media expenditure

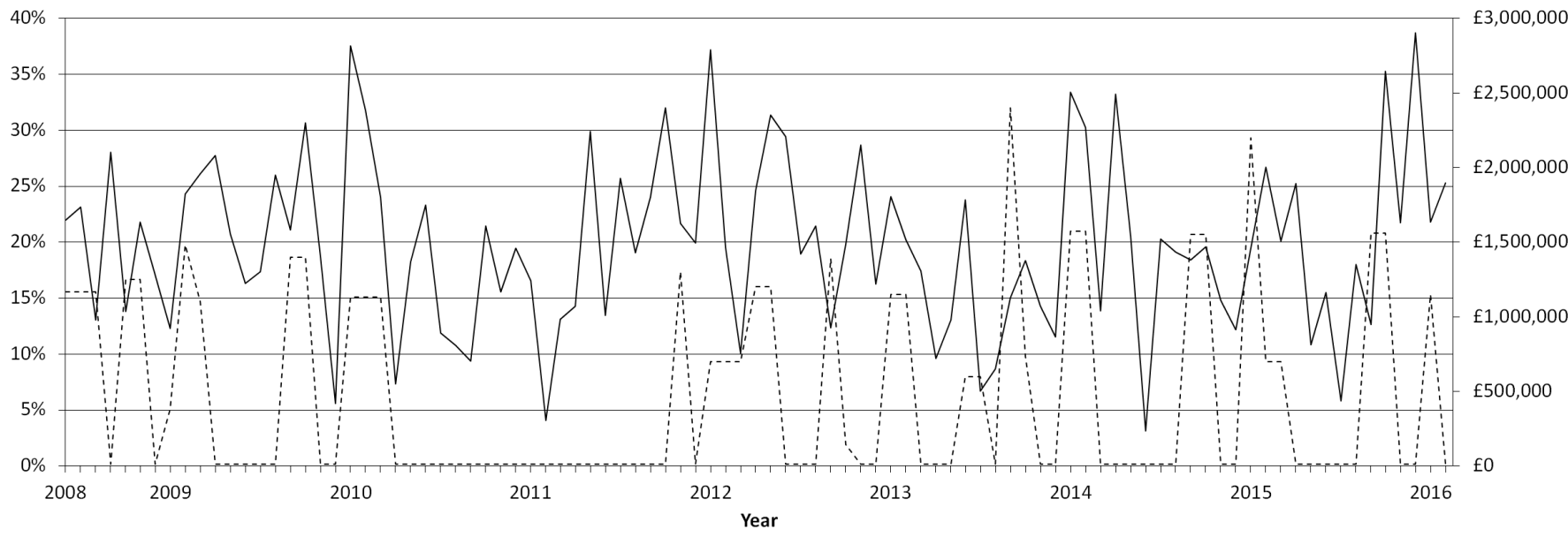

C. Smoking prevalence

_-Smoking prevelance ---Anti-tobacco mass media expenditure

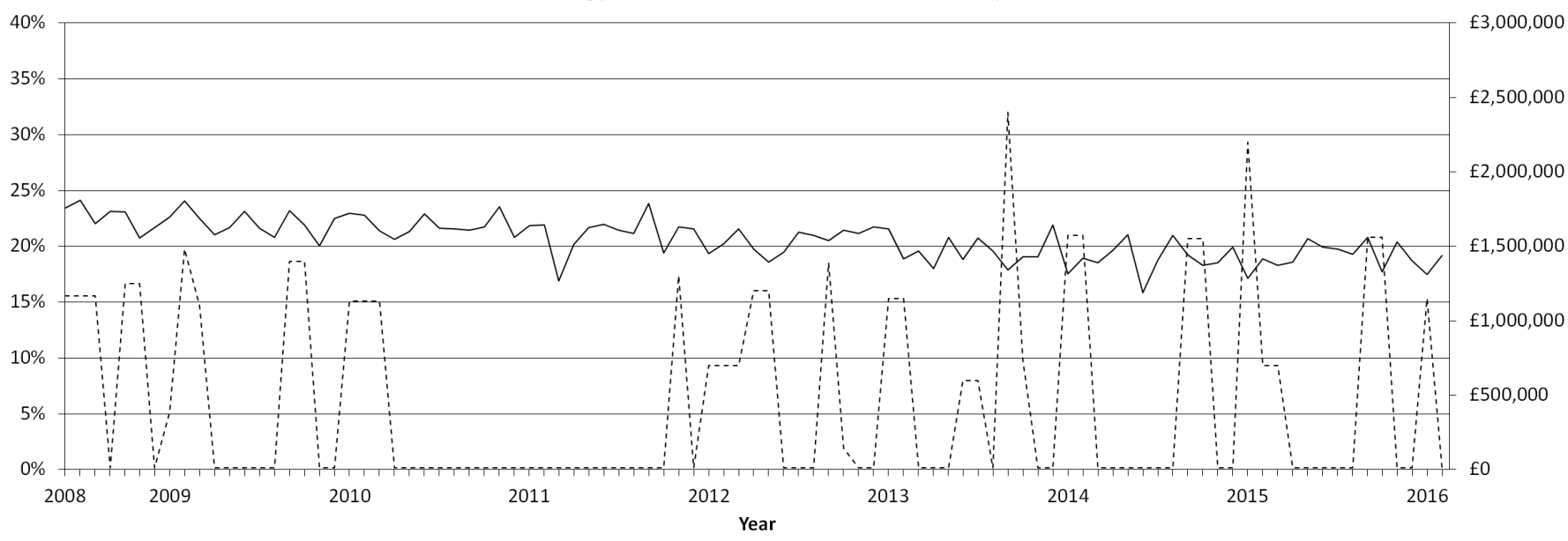

Figure 1 Weighted monthly trends of (A) quit attempts in the last 2 months, (B) quit success in those who attempted in the last 2 months and (C) smoking prevalence in the general population and the expenditure on mass media tobacco control campaigns in pound per month.

\section{Study limitations}

This study had a number of limitations. First, the association observed between expenditure and quit success may not be causal, but due to unmeasured confounding. We attempted to control for major factors that could affect success of quit attempts at a population level, including the rise in popularity of e-cigarettes. ${ }^{33}$ However, it remains possible that our measures were not sufficiently precise or that there was residual confounding. For example, campaigns may influence social norms to be less accepting of smoking, ${ }^{34}$ which increases support for more tobacco control investment and may in turn increase mass media expenditure. However, Granger causality tests 


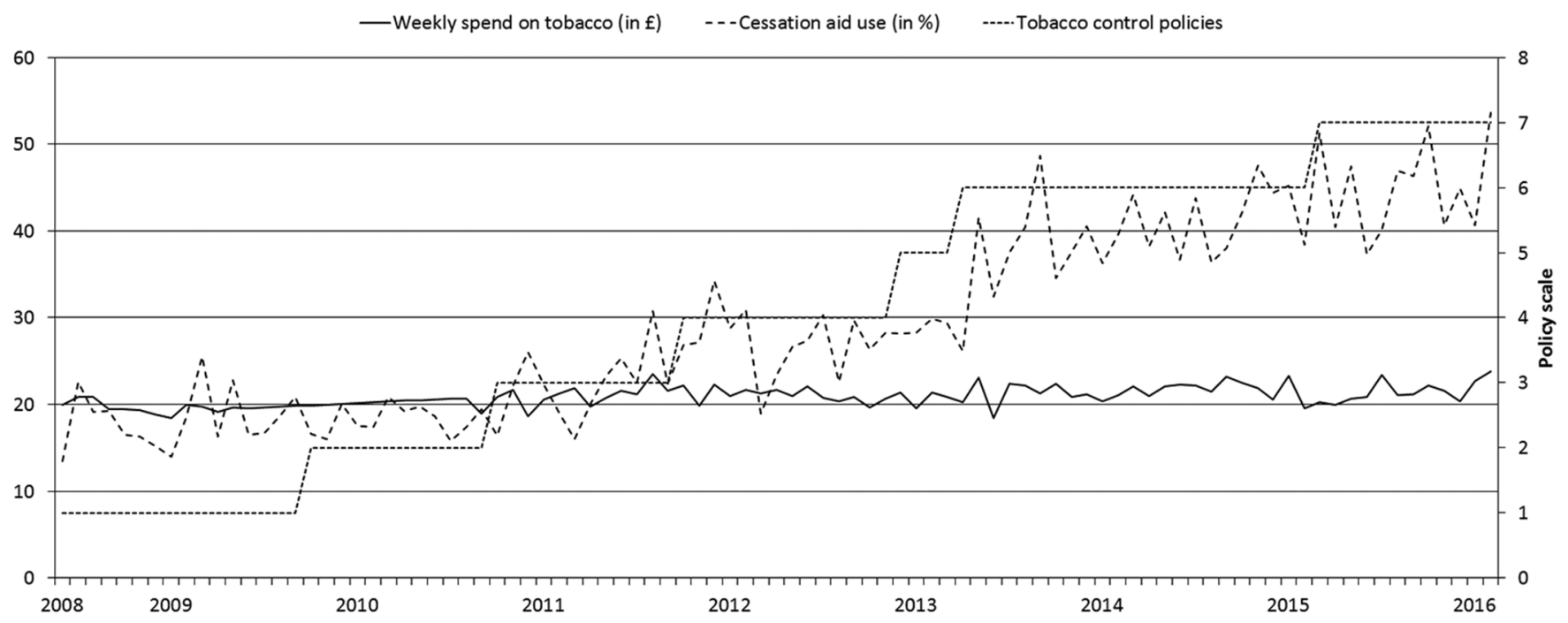

Figure 2 Weighted monthly trends in the use of e-cigarettes, prescription nicotine replacement therapy and prescription medication by smokers who attempted to quit in the last year (in \%), weekly spend on tobacco by smokers (in $\mathrm{f}$ ) and tobacco control policies.

were performed as a part of the ARIMAX analyses and found weak exogeneity between mass media expenditure and all three smoking outcomes.

Second, we relied on self-reports of smoking and quitting. These may be subject to error and bias. For example, failed quit attempts tend to be forgotten relatively quickly, and this could weaken our ability to detect an effect on quit attempts. On the other hand, these measures have shown reliable associations with other factors that influence quitting, such as use of e-cigarettes $^{33}$ and cigarette warning labels. ${ }^{35}$

Third, while the sample was intended to be representative and had characteristics that were similar to other large population samples in England, ${ }^{25}$ it is likely that there is bias in the type of people who respond to these kinds of surveys. This is an important area for study as it appears that there is a reduced willingness on the part of the general public to take part in surveys. ${ }^{36}$

Table 2 Estimated percentage change in quit attempts (the proportion of smokers who attempted to quit in the past 2 months) per $10 \%$ change in mass media expenditure from ARIMAX models

\begin{tabular}{|c|c|c|}
\hline Quit attempts & Unadjusted & Adjusted for covariates in table \\
\hline & $\begin{array}{l}\text { Percentage change per } 10 \% \text { change in the exposure } \\
(95 \% \mathrm{Cl}) \text {, p Value }\end{array}$ & $\begin{array}{l}\text { Percentage change per } 10 \% \text { change in the exposure } \\
(95 \% \mathrm{Cl}) \text {, p Value }\end{array}$ \\
\hline \multicolumn{3}{|l|}{ Model 1} \\
\hline Mass media expenditure (lag 0) & $-0.04(-0.63$ to 0.54$), 0.883$ & $-0.03(-0.62$ to 0.56$), 0.931$ \\
\hline Weekly spend tobacco (lag 4) & & $-0.51(-2.89$ to 1.87$), 0.677$ \\
\hline Tobacco control policies & & $0.06(-0.49 ; 0.62), 0.830$ \\
\hline$-\mathrm{MA}$ & $<0.001$ & $<0.001$ \\
\hline Seasonal (p)-AR & NA & NA \\
\hline -MA & NA & NA \\
\hline$R^{2}$ & 0.010 & 0.012 \\
\hline \multicolumn{3}{|l|}{ Model 2} \\
\hline Non-seasonal $(p)-A R$ & NA & NA \\
\hline -MA & $<0.001$ & $<0.001$ \\
\hline Seasonal $(p)-A R$ & NA & NA \\
\hline$-\mathrm{MA}$ & NA & NA \\
\hline$R^{2}$ & 0.010 & 0.012 \\
\hline
\end{tabular}

The assumption of normally distributed errors was met. When the lag for weekly tobacco spend was set to zero, results for mass media were similar in model $1(\beta=-0.04$

$(-0.63$ to 0.54$), p=0.882)$ or in model 2 ( $\beta=-0.05(-0.66$; to 0.56$), p=0.864)$. Addition of MA or AR terms did not improve the models.

AR, autoregressive terms; ARIMAX, Autoregressive integrated moving average modelling with exogenous variables; $M A$, moving average terms. 
Table 3 Estimated percentage change in quit success (the proportion successful quitters among those who made an attempt in the past 2 months) per $10 \%$ change in mass media expenditure from ARIMAX models

\begin{tabular}{|c|c|c|}
\hline Quit success & Unadjusted & Adjusted for covariates in table \\
\hline & $\begin{array}{l}\text { Percentage change per } 10 \% \text { change in the exposure } \\
(95 \% \mathrm{Cl}), \mathrm{p} \text { Value }\end{array}$ & $\begin{array}{l}\text { Percentage change per } 10 \% \text { change in the exposure } \\
(95 \% \mathrm{Cl}) \text {, p Value }\end{array}$ \\
\hline Mass media expenditure (lag 0) & 0.55 (0.15 to 0.96$), 0.007$ & 0.51 (0.10 to 0.91$), 0.014$ \\
\hline Weekly spend tobacco (lag 0) & & $-16.83(-37.41$ to 3.75$), 0.109$ \\
\hline Cessation aid use (lag 4) & & $2.11(-1.51$ to 5.73$), 0.254$ \\
\hline Non-seasonal (p)-AR & NA & $<0.001$ \\
\hline$-\mathrm{MA}$ & $<0.001$ & NA \\
\hline Seasonal (p)-AR & NA & NA \\
\hline -MA & NA & NA \\
\hline$R^{2}$ & 0.075 & 0.112 \\
\hline
\end{tabular}

Additional MA $(0,1,2)$ or AR $(1,1,1)$ terms were not significant. The assumption of normally distributed errors was met. When all lags were set to zero in the adjusted model, similar results were found for mass media $(\beta=0.50(0.10$ to 0.90$), p=0.015)$. A lag of 1 month for mass media expenditure, although with a considerably worse fit, led to a comparable increase in quit success $(\beta=0.49$ ( 0.10 to 0.87$), p=0.013)$.

$A R$, autoregressive terms; ARIMAX, Autoregressive integrated moving average modelling with exogenous variables; MA, moving average terms.

The results of the current study may be biased if participants are more engaged in societal issues and perhaps more responsive to mass media campaigns than non-participants.

Fourth, the findings represent trends in England over a particular time period with particular kinds of mass media campaigns, and an optimal level of expenditure could not be identified. It is possible that different results would be obtained in other circumstances with different campaign strategies. ${ }^{7} 1137$ This means that the effectiveness of England's future mass media expenditure and expenditure by foreign governments is not guaranteed by our results. However, England's mass media campaign strategy is broadly similar-including use of similar material-to other countries, such as Australia. The fact that the association with quit success was found over a relatively long period of study

Table 4 Estimated percentage change in smoking prevalence (the proportion of smoking in the general population) per $10 \%$ change in the exposure from ARIMAX models

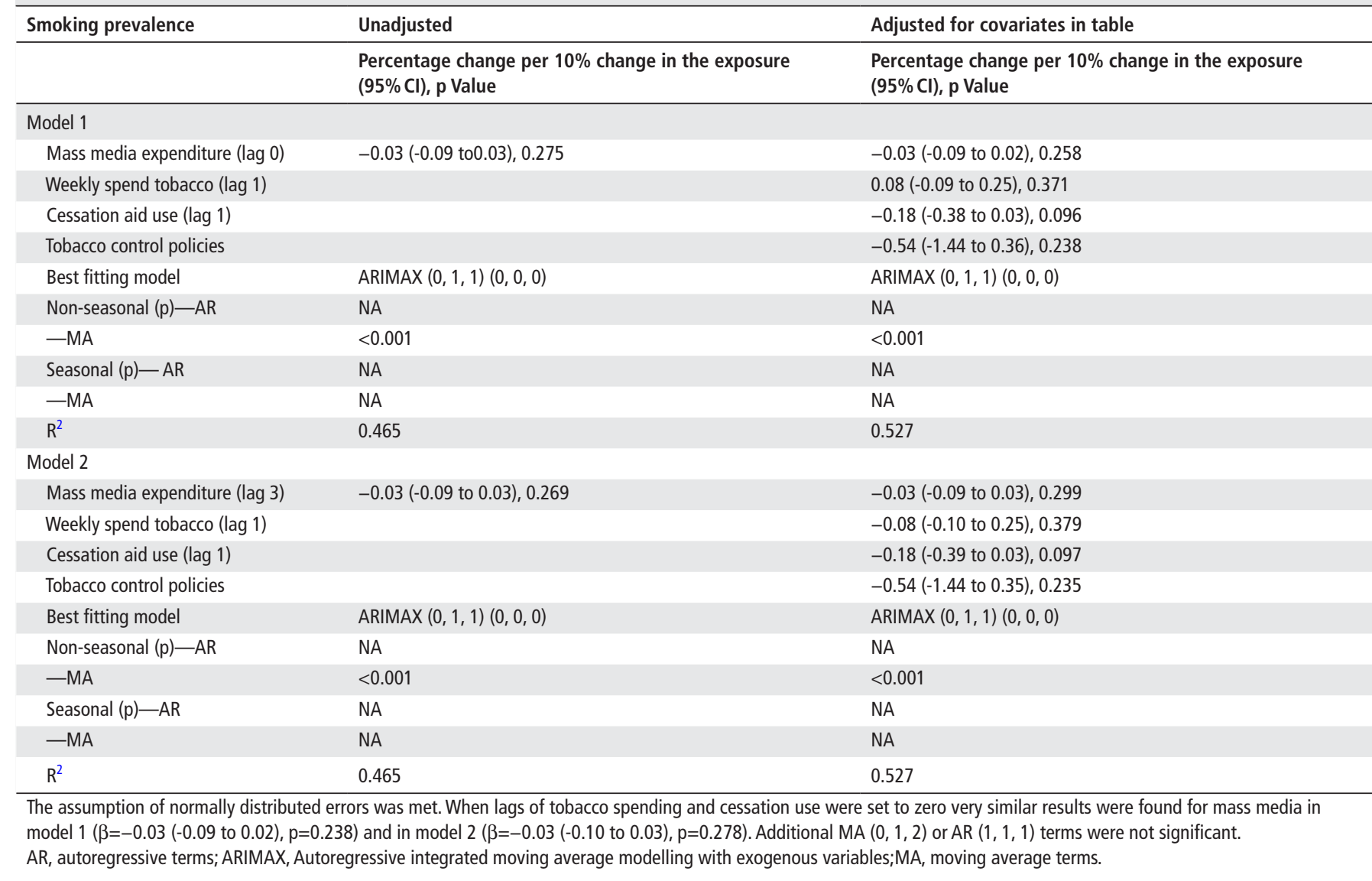


with a variety of different types of campaigns, probably gives a broad indication of what can be achieved by a well-informed campaign strategy. In 2004-2010, 89\% of tobacco control mass media campaigns was for smoking cessation, among which half contained how-to-quit messages. ${ }^{2}$

\section{Interpretation}

Mass media expenditure in England over the period of the study was associated with more successful quitting among those who attempted to stop. This is in line with findings from a controlled trial in four regions in central and northern England, which found that an antismoking TV campaign that provided tips on how to prevent relapse was effective in helping prevent relapse. ${ }^{13}$ Relapse prevention tips were also found to be helpful in a study among ex-smokers in the USA. ${ }^{38}$ Another US study found that tips on how to quit from former smokers increased quit success among smokers making a quit attempt. ${ }^{39}$ Quit success may be increased due to mass media campaigns sustaining motivation to persist with the quit attempt by maintaining the salience of quitting or making quitting appear more normative. ${ }^{44}$ Moreover, smokers may more often seek professional help as a result of how-to-quit messages, such as behavioural or cognitive therapy, support groups, quitlines or other forms of professional support. ${ }^{12}$ This was demonstrated by Langley et al, ${ }^{10}$ showing that stopping mass media spending significantly reduced the number of literature requests, quitline calls and website hits.

If the relationship between mass media expenditure and quit success found in this study is causal, we can estimate that every $10 \%$ increase in expenditure would result in a $0.51 \%$ increase in short-term success rates, other things being equal. The mean quit success rate over the studied period would have been 19.98\% instead of $19.87 \%$ if mass media expenditure was $10 \%$ higher. Over the study period, the monthly average expenditure on mass media campaigns was $£ 465054$, or $£ 5580644$ per year, and according to the STS data $35.3 \%$ of smokers made a quit attempt in the last year. Our data showed that $19.9 \%$ of these quit attempts were successful after 2 months, and according to previous studies $55 \%$ of these quit attempts remained successful after 6 months ${ }^{27}$. With 8 million smokers in England, this amounts to 308638 people $(8000000 \times 0.353 \times 0.199 \times 0.55)$. Thus, our findings suggest that if spending on mass media campaigns were increased by $£ 1$ million per year, there would have been an additional 5129 short-term ex-smokers. Applying an adjustment for subsequent relapse this would translate to 2500 people who stopped smoking permanently. ${ }^{27}$ Assuming that most smokers who would have stopped were in middle age, this amounts to 2903 additional life years gained at a cost of $£ 344$ (95\% CI 193 to 1757 ) per life year using a standard annual discount rate of $3.5 \%{ }^{27}$ This incremental cost-effectiveness ratio of $£ 344$ is comparable with findings from previous cost-effectiveness studies on mass media campaigns. ${ }^{16} 1740-42$

The failure to find a clear association of expenditure with quit attempts seems to conflict with previous studies. ${ }^{4}$ In fact, we cannot conclude that there was no effect of mass media campaign expenditure on quit attempts due to a wide confidence interval (ranging from -2.05 to 2.00 ), and previous studies have yielded mixed results. ${ }^{4} 173943-45$ The circumstances in which mass media campaigns may increase quit attempts or not requires further study.

We did not find a significant association between mass media expenditure and smoking prevalence, although the association was in the expected direction. If the association we found with quit success is causal, the impact on smoking prevalence would
What this paper adds

- While it has been established that mass media campaigns can increase smoking cessation rates, there is little direct evidence estimating associations between government expenditure on tobacco control mass media campaigns and smoking cessation. The current study provides policy-makers with estimates of the impact of governmental investment in tobacco control mass media campaigns.

- Although no clear association was detected between changes in mass media expenditure and changes in quit attempt prevalence or smoking prevalence, higher expenditure on mass media campaigns as a component of a government tobacco control strategy was associated with higher quit success rates.

only result in a $0.03 \%$ reduction in prevalence which we would be unlikely to detect with our sample size.

\section{IMPLICATIONS}

Mass media expenditure is cost-effective at much lower costs than generally accepted thresholds for public health interventions: for example $£ 20000$ as stated in the UK's National Institute for Health and Care Excellence guidelines. ${ }^{46}$ Mass media expenditure in England has not increased since lifting the 2011 moratorium, and the English Department of Health announced a budget of $£ 4$ million for 2016/2017, compared with $£ 5.3$ million in $2015 / 2016$, a cut of $25 \% .{ }^{47}$ This could lead to 3251 fewer long-term ex-smokers. Increased expenditure on mass media campaigns, on the other hand, has the potential to reduce smoking, to gain life years and to have a positive return on investment. ${ }^{48}$

\section{CONCLUSIONS}

Between 2008 and 2016, higher expenditure on tobacco control mass media campaigns in England was associated with an increase in quit success rates. An association with quit attempts and smoking prevalence was not clearly established. For an additional million pounds spent per year over and above expenditure across the period, we estimate there could have been 2500 additional permanent ex-smokers.

Correction notice This paper has been amended since it was published Online First. Owing to a scripting error, some of the publisher names in the references were replaced with 'BMJ Publishing Group'. This only affected the full text version, not the PDF. We have since corrected these errors and the correct publishers have been inserted into the references.

Acknowledgements The authors acknowledge the help of Dr Nigel Shardlow (Sandtable Ltd), Bernard Kujawski (Sandtable Ltd) and Matthew Walmsley (Public Health England) for their roles in initiating this study. Matthew Walmsley is also gratefully acknowledged for providing data on mass media expenditure.

Contributors MK, EB, RW and JB designed the study. EB and MK conducted the analyses and MK wrote the first draft. All authors commented on this draft and contributed to the final version. MK is guarantor.

Funding The Smoking Toolkit Study is currently primarily funded by Cancer Research UK (C1417/A14135; C36048/A11654; C44576/A19501) and has previously also been funded by Pfizer, GSK and the Department of Health. MK is funded by a research grant of the NCSCT and a EC Horizon 2020 grant (SILNE-R grant agreement no. 635056); EB is funded by a fellowship from the NIHR SPHR (SPHR-SWP-ALC-WP5) and CRUK also provide support (C1417/A14135); RW is funded by Cancer Research UK (C1417/A14135); JB's post is funded by a fellowship from the Society for the Study of Addiction and CRUK also provides support (C1417) A14135). SPHR is a partnership between the universities of Sheffield, Bristol, Cambridge, Exeter, UCL and The London School for Hygiene and Tropical Medicine. 
Disclaimer The views expressed are those of the authors(s) and not necessarily those of the NHS, NIHR or Department of Health. No funder had any involvement in the design of the study, the analysis or interpretation of the data, the writing of the report or the decision to submit the paper for publication.

Competing interests RW undertakes consultancy and research for and receives travel funds and hospitality from manufacturers of smoking cessation medications (Pfizer, J\&J and GSK) but does not take funds from e-cigarettes manufacturers or the tobacco industry. $E B$ and JB have received unrestricted research funding from Pfizer. $E B$ and JB are funded by CRUK. EB is also funded by NIHR's SPHR and JB by the Society for the Study of Addiction. MK has no competing interests to declare.

Patient consent Obtained.

Ethics approval University College London ethics committee (ID 0498/001).

Provenance and peer review Not commissioned; externally peer reviewed.

Open access This is an open access article distributed in accordance with the terms of the Creative Commons Attribution (CC BY 4.0) license, which permits others to distribute, remix, adapt and build upon this work, for commercial use, provided the original work is properly cited. See: http://creativecommons.org/licenses/by/4.0/

(c) Article author(s) (or their employer(s) unless otherwise stated in the text of the article) 2018. All rights reserved. No commercial use is permitted unless otherwise expressly granted.

\section{REFERENCES}

1 World Health Organization. Framework convention on tobacco control. Geneva: World Health Organization, 2003.

2 Langley T, Lewis S, McNeill A, et al. Characterizing tobacco control mass media campaigns in England. Addiction 2013;108:2001-8.

3 Hoffman SJ, Tan C. Overview of systematic reviews on the health-related effects of government tobacco control policies. BMC Public Health 2015;15:1.

4 Durkin S, Brennan E, Wakefield M. Mass media campaigns to promote smoking cessation among adults: an integrative review. Tob Control 2012;21:127-38.

5 Bala M, Strzeszynski L, Cahill K. Mass media interventions for smoking cessation in adults. Cochrane Database Syst Rev 2008;1:CD004704.

6 Abroms LC, Maibach EW. The effectiveness of mass communication to change public behavior. Annu Rev Public Health 2008;29:219-34.

7 Sims M, Langley T, Lewis S, et al. Effectiveness of tobacco control television advertisements with different types of emotional content on tobacco use in England, 2004-2010. Tob Control 20162013;25:051454.

8 Sims M, Salway R, Langley T, et al. Effectiveness of tobacco control television advertising in changing tobacco use in England: a population-based cross-sectional study. Addiction 2014;109:986-94.

9 Wakefield MA, Durkin S, Spittal MJ, et al. Impact of tobacco control policies and mass media campaigns on monthly adult smoking prevalence. Am J Public Health 2008;98:1443-50

10 Langley T, Szatkowski L, Lewis S, et al. The freeze on mass media campaigns in England: a natural experiment of the impact of tobacco control campaigns on quitting behaviour. Addiction 2014;109:995-1002.

11 Richardson S, Langley T, Szatkowski L, et al. How does the emotive content of televised anti-smoking mass media campaigns influence monthly calls to the NHS Stop Smoking helpline in England? Prev Med 2014;69:43-8.

12 Langley TE, McNeill A, Lewis S, et al. The impact of media campaigns on smoking cessation activity: a structural vector autoregression analysis. Addiction 2012; 107:2043-50.

13 McVey D, Stapleton J. Can anti-smoking television advertising affect smoking behaviour? controlled trial of the Health Education Authority for England's antismoking TV campaign. Tob Control 2000;9:273-82.

14 All Party Parliamentary Group on Smoking and Health. representation to the 2015 spending review. London: Action on Smoking and Health, 2015.

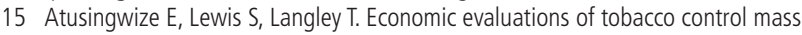
media campaigns: a systematic review. Tob Control 2015;24:320-7.

16 Ratcliffe J, Cairns J, Platt $\mathrm{S}$. Cost effectiveness of a mass media-led anti-smoking campaign in Scotland. Tob Control 1997;6:104-10.

17 Brown J, Kotz D, Michie S, et al. How effective and cost-effective was the national mass media smoking cessation campaign 'Stoptober'? Drug Alcohol Depend 2014;135:52-8.

18 Villanti AC, Curry LE, Richardson A, et al. Analysis of media campaign promoting smoking cessation suggests it was cost-effective in prompting quit attempts. Health Aff 2012;31:2708-16.

19 Hurley SF, Matthews JP. Cost-effectiveness of the Australian National Tobacco Campaign. Tob Control 2008;17:379-84.
20 Farrelly MC, Hussin A, Bauer UE. Effectiveness and cost effectiveness of television, radio and print advertisements in promoting the New York smokers' quitline. Tob Control 2007;16(Suppl 1):i21-3.

21 Farrelly MC, Pechacek TF, Chaloupka FJ. The impact of tobacco control program expenditures on aggregate cigarette sales: 1981-2000. J Health Econ 2003:22:843-59.

22 Kotz D, Stapleton JA, Owen L, et al. How cost-effective is 'No Smoking Day'? Tob Control 2011:20:302-4.

23 Centers for Disease Control and Prevention. Best Practices for Comprehensive Tobacco Control Program. Atlanta, 2014.

24 Joossens L, Raw M. The tobacco contro/ scale 2013 in Europe. Brussels: Association of European Cancer Leagues, 2014.

25 Fidler JA, Shahab L, West 0, et al. 'The smoking toolkit study': a national study of smoking and smoking cessation in England. BMC Public Health 2011;11:1.

26 Berg CJ, An LC, Kirch M, et al. Failure to report attempts to quit smoking. Addict Behav 2010;35:900-4.

27 Stapleton JA, West R. A direct method and ICER tables for the estimation of the costeffectiveness of smoking cessation interventions in general populations: application to a new cytisine trial and other examples. Nicotine Tob Res 2012;14:463-71.

28 Action on Smoking and Health. Stoptober: ASH calls for more mass media campaigns to help smokers to quit 2016 http://ash.org.uk/media-and-news/press-releasesmedia-and-news/stoptober-ash-calls-for-more-mass-media-campaigns-to-helpsmokers-to-quit/\#_ftn1

29 Kotz D, Brown J, West R. 'Real-world' effectiveness of smoking cessation treatments: a population study. Addiction 2014;109:491-9.

30 Brown J, Beard E, Kotz D, et al. Real-world effectiveness of e-cigarettes when used to aid smoking cessation: a cross-sectional population study. Addiction 2014; 109:1531-40.

31 Box GE, Jenkins GM, Reinsel GC, et al. Time series analysis: forecasting and control: john Wiley \& Sons, 2015.

32 von Elm E, Altman DG, Egger M, et al. The Strengthening the Reporting of Observational Studies in Epidemiology (STROBE) statement: guidelines for reporting observational studies. Prev Med 2007;45:247-51.

33 Beard E, West R, Michie S, et al. Association between electronic cigarette use and changes in quit attempts, success of quit attempts, use of smoking cessation pharmacotherapy, and use of stop smoking services in England: time series analysis of population trends. BMJ 2016;354:i4645.

34 Wakefield MA, Loken B, Hornik RC. Use of mass media campaigns to change health behaviour. Lancet 2010;376:1261-71.

35 Azagba S, Sharaf MF. The effect of graphic cigarette warning labels on smoking behavior: evidence from the Canadian experience. Nicotine Tob Res 2013;15:708-17.

36 Mindell JS, Giampaoli S, Goesswald A, et al. Sample selection, recruitment and participation rates in health examination surveys in Europe--experience from seven national surveys. BMC Med Res Methodol 2015;15:1.

37 Richardson S, McNeill A, Langley TE, et al. The impact of televised tobacco control advertising content on campaign recall: evidence from the International Tobacco Control (ITC) United Kingdom Survey. BMC Public Health 2014;14:1.

38 Biener L, Reimer RL, Wakefield M, et al. Impact of smoking cessation aids and mass media among recent quitters. Am J Prev Med 2006;30:217-24.

39 McAfee T, Davis KC, Alexander RL, et al. Effect of the first federally funded US antismoking national media campaign. Lancet 2013;382:2003-11.

40 Fishman PA, Ebel BE, Garrison MM, et al. Cigarette tax increase and media campaign cost of reducing smoking-related deaths. Am J Prev Med 2005;29:19-26.

41 Secker-Walker RH, Worden JK, Holland RR, et al. A mass media programme to prevent smoking among adolescents: costs and cost effectiveness. Tob Control 1997;6:207-12.

42 Raikou M, McGuire A. Cost-effectiveness of a mass media campaign and a point of sale intervention to prevent the uptake of smoking in children and young people: economic modelling report. LSE Health 2008

43 Farrelly MC, Duke JC, Davis KC, et al. Promotion of smoking cessation with emotional and/or graphic antismoking advertising. Am J Prev Med 2012;43:475-82.

44 Wakefield MA, Spittal MJ, Yong HH, et al. Effects of mass media campaign exposure intensity and durability on quit attempts in a population-based cohort study. Health Educ Res 2011;26:988-97.

45 Vallone DM, Duke JC, Cullen J, et al. Evaluation of EX: a national mass media smoking cessation campaign. Am J Public Health 2011;101:302-9.

46 NICE. Methods for the development of NICE public health guidance (third edition), Chapter 6.4 Economic evidence and guidance recommendations. 2012 https://www. nice.org.uk/process/pmg4/chapter/6-incorporating-health-economics\#economicevidence-and-guidance-recommendations (accessed 8 August 2016).

47 House of Lords Hansard. Smoking-Related Diseases 2016;774.

48 De Kinderen RW, Hiligsmann FM, Paulus M, et al. Social cost-benefit analysis of tobacco control policies in the Netherlands: Maastricht University, 2016. 